\section{البصيرة: مبلة الصراهات الإهلامية \\ AL-BASSHIRAH: JOURNAL OF ISLAMIC STUIDES \\ Vol. 1 No. 1(2020): 85-96}

Website: https://journal.stiba.ac.id

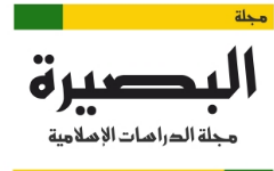

AL-BASHIRAH

\title{
الطريقة المثلى في تعليم القواعد النحوية للمبتدئين والمتقدمين \\ لغير الناطقين بها
}

\author{
روني محمود الدين \\ المعهد العالي للدراسات الإسلامية والعربية بمكسر المبرس
}

البريد الإلكتووني: ronny.mahmuddin@stiba.ac.id

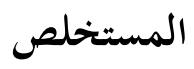

يستهدف هذا البحث إلى معرفة ووصف الطريقة المثلى في تعليم القواعد النحوية للمبتدئين والمتقدمين لغير الناطقين هما، وأما نوع هذا البحث فهو البحث الوصفي الكيفي باستخدام الطريقة المكتبية بالعثور على المصادر

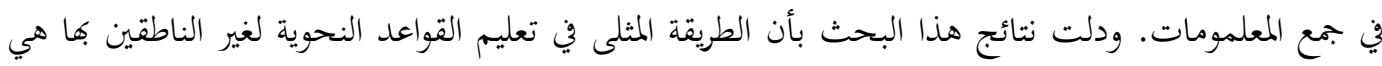

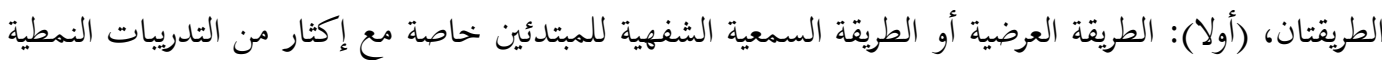

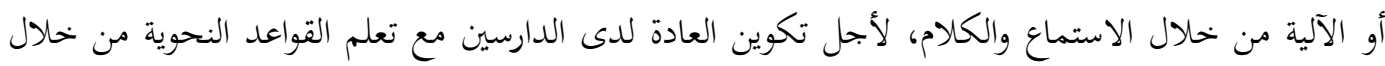
اليساق، و(ثانيا): الطريقة القاصدة أو الطريقة الاستقرائية للمتقدمين وهي الطريقة التي جعلت النص الحواري محورا

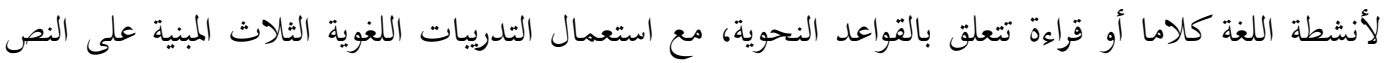

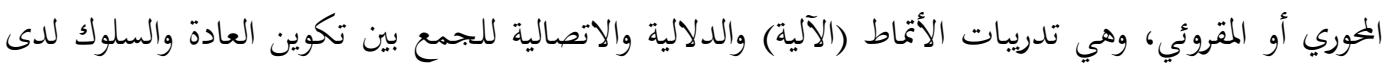
الدارسين مع فهم المعنى والقدرة على المحادثة مع أصحاب اللغة بمراعاة القواعد النحوية النظرية والتطبيقية. الكلمة الدالة: الطريقة السمعية الشفهية، الطريقة الاستقرائية، القواعد النحوية، التدرييات.

\section{The Ideal Method in Learning Rules of Nahwu for Beginners and Advanced Students for Non-Arabic Speakers}

\section{Ronny Mahmuddin}

Sekolah Tinggi Ilmu Islam dan Bahasa Arab (STIBA) Makassar, Indonesia

Email: ronny.mahmuddin@stiba.ac.id

\section{Abstract}

This study aimed to identify and describe the best method of teaching rules of nahwu for beginners and advanced students for foreign speakers (non-Arabic). This research was a qualitative descriptive study with a type of library research by tracing references in data collection. The results of this study indicate that the best method of teaching rules of nahwu for foreign speakers is of two methods, namely: The first one is the aural-oral method (sam'iyyah

$$
\text { روني محمود الدين ,الطريقة المثلى في تعليم القواعد النحوية للمبتدئين والمتقدمين لغير الناطقين بها }
$$




\section{البصيرة: مبلة الدراهات الإهلامية \\ AL-BASHIRAH: JOURNAL OF ISLAMIC STUIDES \\ Vol. 1 No. 1(2020): 85-96}

Website: https://journal.stiba.ac.id

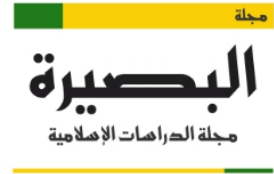

AL-BASHIRAH

syafawiyyah) for the beginner level. This method uses patterned training techniques (pattern drill) through activities of istimā' (listening) and kalām (speaking) to form behavior (habits) for beginner-level learners in using language along with learning rules of nahwu through sentence structure (applied nahwu); The second one is the method of al-istiqra'iyyah (inductive method) for advanced students. This method is one that makes the dialogue/reading text the center of learning all language skills, both speaking and reading related to the rules of nahwu by using three training techniques (drill) that do not come out of the dialogue/reading text, namely the pattern drill (patterned training), meaning drill (exercise of the meaning) and communicative drill (communication exercise). These three techniques combine the formation of behavioral habits in using language along with understanding the meaning and ability to communicate with native speakers (Arabs) by paying attention to the theoretical principles of nahwu (nahwu concept) and applied nahwu (applied nahwu).

Keywords: Aural-Oral Method, Inductive Method, Rules of Nahwu, Exercise.

المقدمة

إن الله سبحانه وتعالى قد اختار اللغة العربية من سائر اللغات لحمل رسالة الإسالام على

كافة الناس، وذكر الله في القرآن الكريم على عربية القرآن في عدة آيات ومنها، قوله جلا وعلى: \} إنا أنزلناه قرآنا عربيا لعلكم تعقلون سورة الشعراء: 90 ا . كثير من المسلمين عربيا وأعجميا اهتموا بتعلم اللغة العربية وتعليمها، وعنايتهم بتلك اللغة المشرفة في الزمان القديم والحديث- لما عدة أسباب، منها: أن اللغة العربية من الدين ومعرفتها فرض واجب، فإن فهم الكتاب والسنة فرض، ولا يفهم إلا باللغة العبية، وما لا يتم الواحب إلا به فهو واجب.

اللغة عنوان ثقافة الأمة وحضارةا، ولذلك الأمم كافة بلغاتًا وتعمل على ترقيتها. بُ واللغة تعتبر من أهم المعايير التي تقاس بها فاعلية الأمم في مضمار التقدم والحضارة والتأثير والتأثر، ويقدر ما لهذه اللغة من أصالة وحيوية وانتشار وقدرة على مسايرة روح العصر والتعبير عما يجد فيه معان وعلوم ومصطلحات بقدر ما يكون لأصحاب هذه اللغة من مكانة عالية ودور عظيم في مضمار التقدم الحضاري بمختلف نواحيه.

$$
\begin{aligned}
& \text { 'ابن تيمية الحراني، اقتضاء الصراط المستقيم (دون الطبعة؛ بيروت: دار عالم الكتب، } 9 \text { اع اهـ/999 (م) ص. به م. }
\end{aligned}
$$

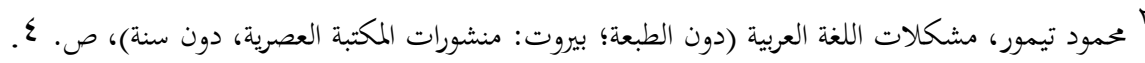

"َ محمود كامل ناقة، تعليم اللغة العربية للناطقين بلغات أخري - أسسه ومداخله وطرق تدريسه- (دون الطبعة؛ المملكة

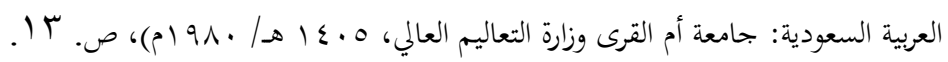

روني محمود الدين ,الطريقة المثلى في تعليم القواعد النحوية للمبتدئين والمتقدمين لغير الناطقين بها 


\section{البصيرة: مبلة الصراهات الإهلامية AL-BASHHIRAH: JOURNAL OF ISLAMIC STUIDES \\ Vol. 1 No. 1(2020): 85-96}

Website: https://journal.stiba.ac.id

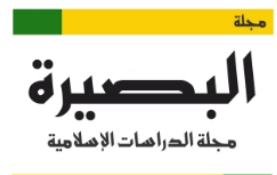

AL-BASHIRAH

والذي له حق التقدم من العلوم العربية هو علم النحو إذ به يعرف صواب الكلام من

خطئه ويستعان بواسطته على فهم سائر العلوم. أن العرب لما علت كلماهم بالإسلام، وانتشرت رايتهم في بلاد فارس والروم وفتحوا بلادهم واختلطوا بهم في المصاهرة والمعاملة والتجارة والتعليم،

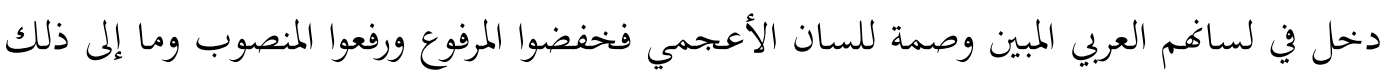
من كثرة اللحن الشنيع حتى كاد أسلوب النطق العربي يتلاشى لأسباب كثيرة.

كان الاتحاه السائد في تدريس القواعد أن تستغرق دروسه ساعات طويلة، يقضيها المدرس في الشرح والتفصيل، بينما ينحصر درو الطلبة في بحرد الاستماع على طريقة القواعد والترجمة. وفي أواخر الخمسينيات وجزء كبير من الستينيات من القرن الماضي، ظهرت الحركة التي عرفت باسم الطريقة السمعية الشفوية، كانت رد فعل مباشر لأسلوب الشرح المفصل. فنادى كثير من خبراء

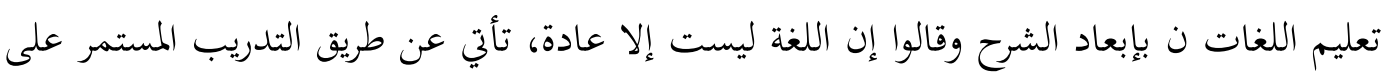

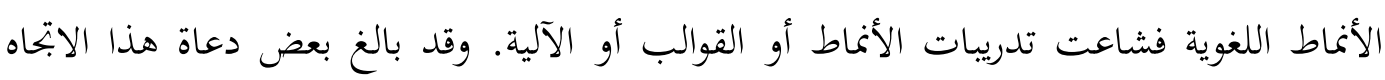
فزعم أن التدريب على القوالب هو الوسيلة الوحيدة إلى تعليم اللغة الأجنبية وقواعدها. ولكن يبدو أن الإغراق في التدريبات النمطية أو الآلية ربما ساعد الدارسين على إجادة بعض الأنماط أو الصيغ النحوية، ولكن كثيرا من هؤلاء وجد نفسه عاجزا عن التعبير عما في نفسه، فكان الهجوم المضاد على هذا النوع من التدريبات من أصحاب الاتحاه المسمى بابحاه المعرفة القائل بأن اللغة سلوك تحمه القواعد فنادى هذا الاتحاه بضرورة فهم الدارسين القواعد اللغوية وطرح التدريبات على الأنماط. ْذ ذكر علي أحمد مدكور أنه لا مراء أن الغاية من تدريس النحو للأطفال والكبار هي إقامة اللسان وبتحب اللحن في الكلام، فإذا قرأ الدارس أو تحدث أو كتب جاءت الت لغته سليمة وواضحة ومحققة للهدف منها. إن الغرض من تدريس النحو هو تكوين الملكة اللسانية الصحيحة لا حفظ القواعد البحردة.

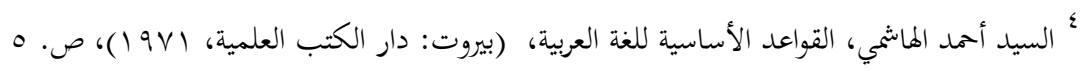

هعبد الرحمن بن إبراهيم الفوزان ، إضاءات لمعلمي اللغة العربية لغير الناطقين بها (الطبعة الأولى؛ الرياض: مكتبة الملك

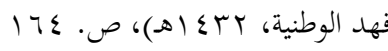

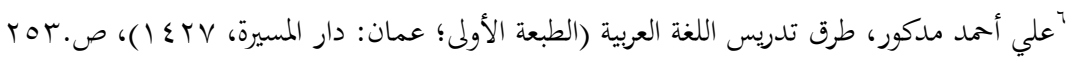

روني محمود الدين ,الطريقة المثلى في تعليم القواعد النحوية للمبتدئين والمتقدمين لغير الناطقين بها 


\section{البصيرة: مبلة الصراهات الإهلامية AL-BASHIRAH: JOURNAL OF ISLAMIC STUIDES \\ Vol. 1 No. 1(2020): 85-96}

Website: https://journal.stiba.ac.id

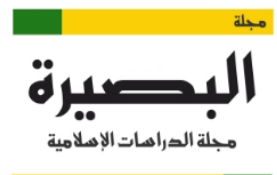

AL-BASHIRAH

بناء على هذا، فلا بد من إيجاد طريقة مثلى أو أسلوب أنسب في الجمع بين الاتحاهين

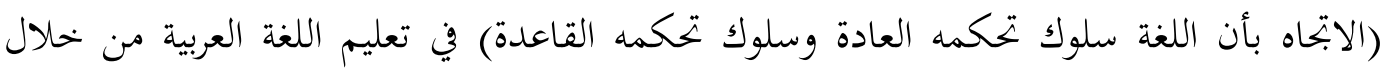

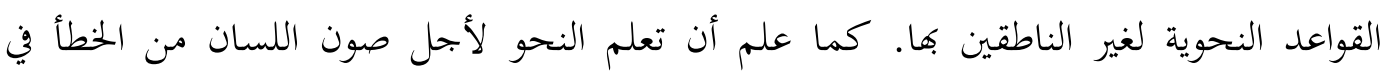
الكلام والكتابة، وكذلك لا يغفل على أهمية تطبيق الكلام بالطلاقة مع مراعاة القواعد النحوية.

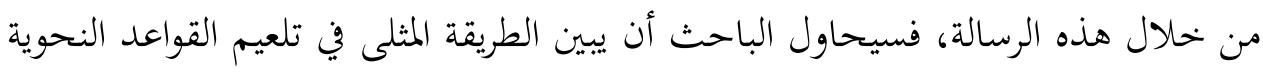

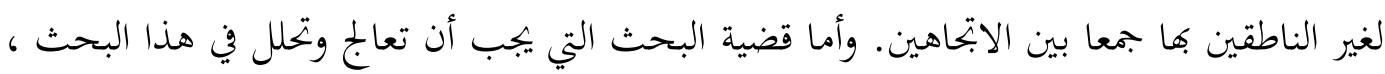

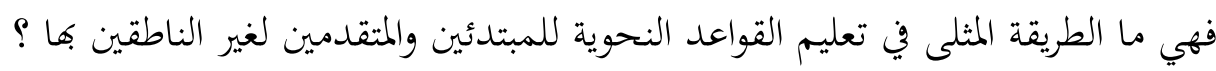

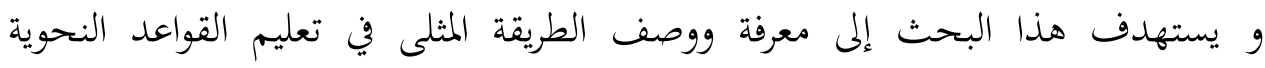

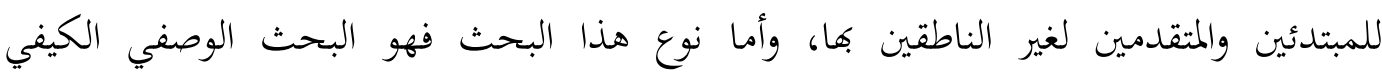

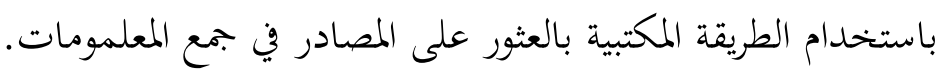

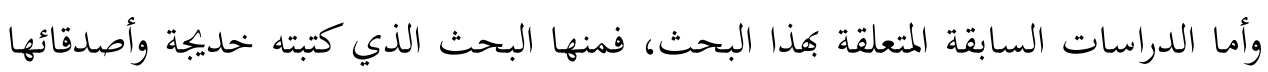
بعنوان "طرائق تدريس النحو"، والهدف من البحث هو وصف طرائق تدريس النحو، وأما نتائج

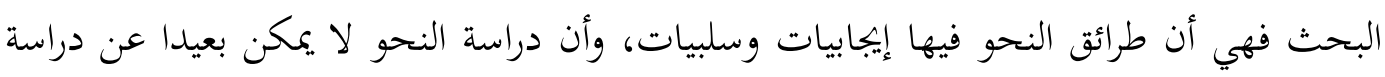

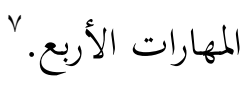

وكذلك البحث الذي له علاقة هذذا البحث هو البحث الذي كتبه أحمد شهري بعنوان

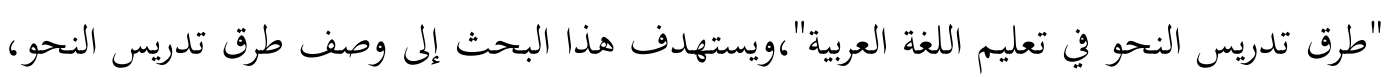
ونتيجة البحث هي أن أبخع طرق في تعليم النحو هي طريقة استقرائية تحليلية نقدية.

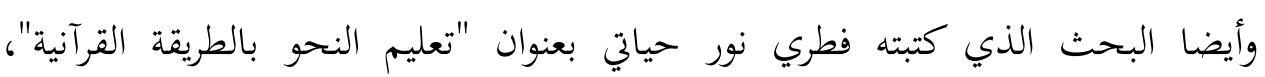

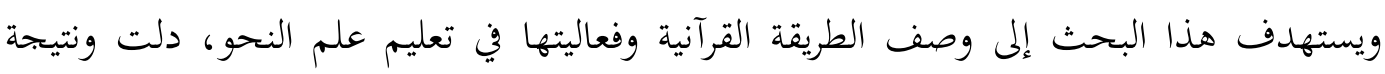
البحث على أن الطريقة القرآنية هي من أنفع طريقة في تدريس النحو لكثرة الأمثلة في القرآن.

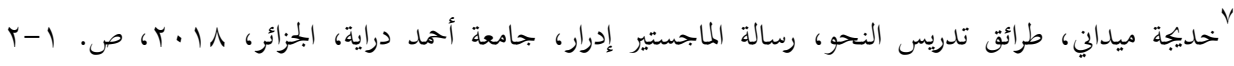

https://dspace.univ-adrar.edu.dz/jspui/handle/123456789/310 Ahmad Sehri, Metode Pengajaran Nahwu dalam Pembelajaran Bahasa ${ }^{\wedge}$ Arab, Jurnal Hunafa, Vol.7, No. 1, April 2010, h. 48-60. https://jurnalhunafa.org/index.php/hunafa/article/view/108

$$
\text { روني محمود الدين ,الطريقة المثلى في تعليم القواعد النحوية للمبتدئين والمتقدمين لغير الناطقين بها }
$$




\section{البصيرة: مبلة الصراهات الإهلامية AL-BASHIRAH: JOURNAL OF ISLAMIC STUIDES \\ Vol. 1 No. 1(2020): 85-96}

Website: https://journal.stiba.ac.id

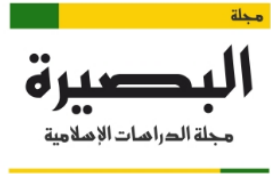

AL-BASHIRAH

لم يجد الباحث - حسب التطلع على الرسائل والدراسات العلمية- من قام بالبحث في

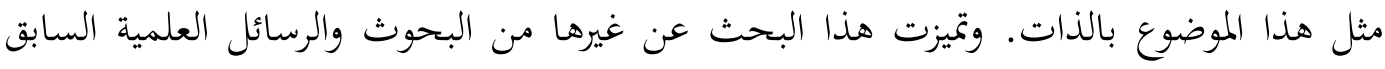

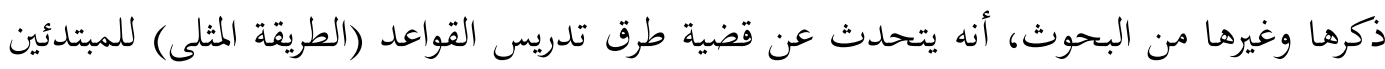

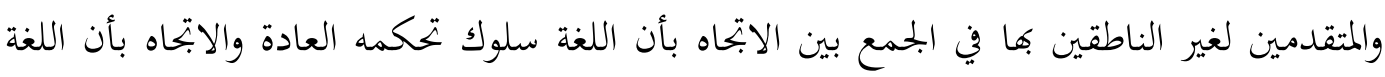

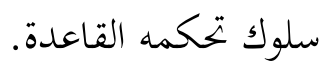

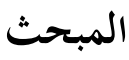

ذكر عبد العليم إبراهيم أن بعض المربين يرون إمكان الاستغناء عن تدريس القواعد في

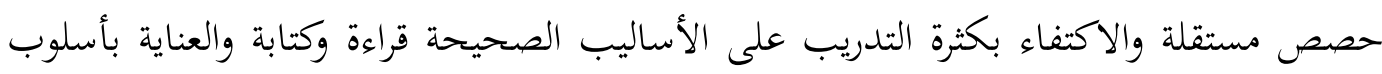

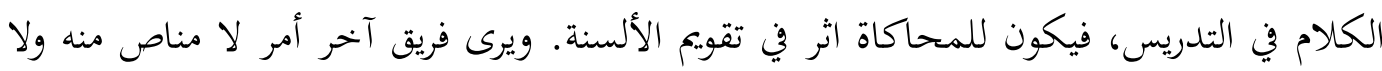

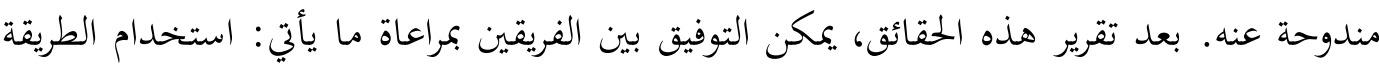

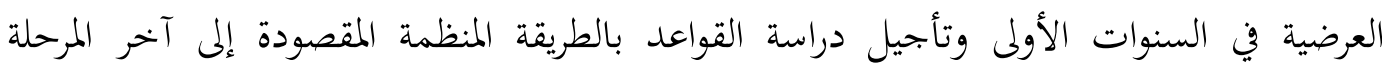

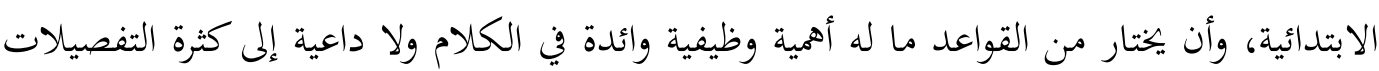
وسرد المذاهب المختلفة، وحفظ الصيغ المعهودة. '. بناء على قول عبد العليم السابق وغيره من المتخصصين في تعليم العربية لغير الناطقين بها،

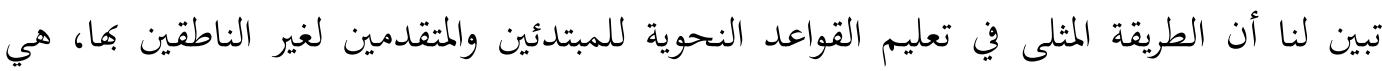

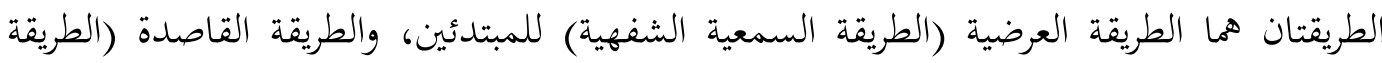
الاستقرائية) للمتقدمين.

القسم الأول: الطريقة العرضية (الطريقة السمعية الشفهية) في تعليم القواعد النحوية للمبتدئين

Fitri Nurhayati, Pembelajaran Ilmu Nahwu Dengan Metode Qur'ani,

Jurnal al-Urwatul Wustqa, Vol.I, No.1, 2020, h.1-4. https://ejournal.stitalhidayah.ac.id/index.php/jurnalalurwatulwutsqo/article/view/4/4

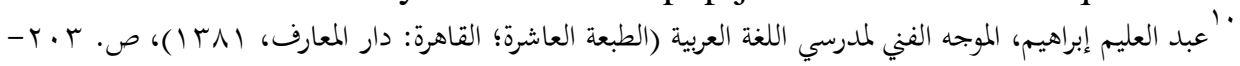




\section{البصيرة: مبلة الصراهات الإهلامية AL-BASHIRAH: JOURNAL OF ISLAMIC STUIDES \\ Vol. 1 No. 1(2020): 85-96}

Website: https://journal.stiba.ac.id

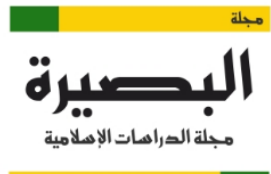

AL-BASHIRAH

JOURNAL OF ISLAMIC STUDIES

ذكر عبد الرحمن الفوزان أن من أهم أسس هذه الطريقة (الطريقة السمعية الشفهية)، هي

أستعمال الوسائل السمعية والبصرية بصورة مكثفة واستخدام أساليب متنوعة لتعليم اللغة، مثل

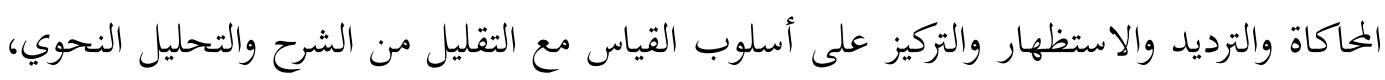

وبدلا من ذلك يتم تدريب الدارسين تدريبا مركزا على أنماط اللغة وتراكيبها النحوية.' ذكر علي مدكور مؤكدا لكلام الفوزان السابق، أن من أهم الأهداف في تعليم القواعد

النحوية في المرحلة الابتدائية هي أن يتعرف الدارس على نسق الجملة العربية وأن يستطيع استعمال الألفاظ والتراكيب استعمالا سليما، وأن يكتسب العادات اللغوية السليمة عن طريق الاستماع والمحاكاة وكثرة الاستعمال. ب' وأكد كذلك عبد العليم إبراهيم الغرض من تعليم القواعد أها وسيلة لضبط الكالام وصحة النطق والكتابة، وليست غاية مقصودة لذاتما, وقد أخطأ كثير من المعلمين حين غالوا بالقواعد، واهتموا بجمع شواهدها والإلمام بتفاصيلها، والإثقال .هذا كله على التلاميذ، ظنا منهم أن في ذلك تمكينا للتلاميذ من لغتهم وإقدارا لهم على إجادة التعبير والبيان. بّا وذكر محمود الناقة أن تعلم اللغة عن طريق الممارسة والتدريب في الطريقة السمعية الشفهية قد أثبت بناحا وفعالية.

بناء على كلام المتخصصين في تعليم اللغة كالفوزان وعبد العليم و علي مدكور وغيرهم، فرأى الباحث أن الطريقة المثلى في تعليم القواعد النحوية للدارسين المبتدئين لغير الناطقين بها هي الطريقة العرضية (الطريقة السمعية الشفهية) مع إكثار من التدريبات اللغوية الآلية لتكوين العادة والسلوك لدى الدارسين من المحاكاة والترديد والسياق.

لهذه الطريقة ملامح فأهم ملامح هذه الطريقة (الطرريقة السمعية الشفهية) عند الفوزان: ترى الطريقة أن اللغة هي الكام، تقدم المهارات بشكل متدرج (استماع - تحدث - قراءة كتابة)، تركز على تطق الأصوات، تقدم النصوص على شكل حوارات، نعلم المفردات من السياق،

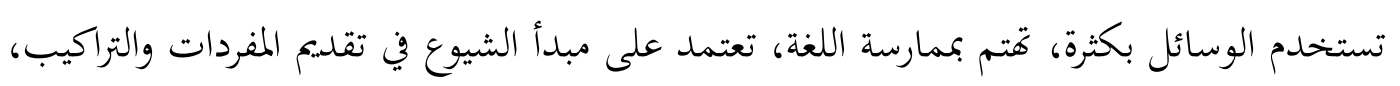

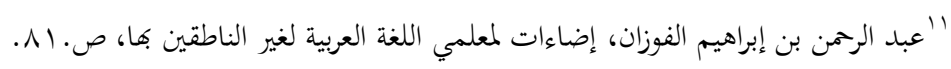

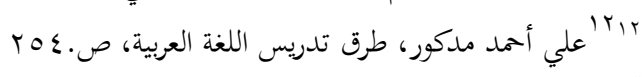

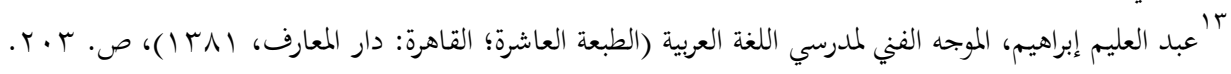

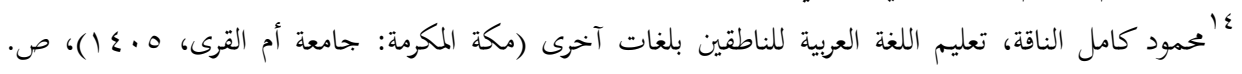




\section{البصيرة: مبلة الصراهات الإهلامية AL-BASHHIRAH: JOURNAL OF ISLAMIC STUIDES \\ Vol. 1 No. 1(2020): 85-96}

Website: https://journal.stiba.ac.id

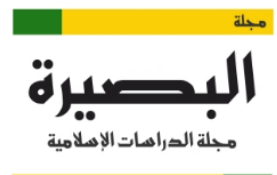

AL-BASHIRAH

وتمتم بالصحة اللغوية والنطق الصحيح للأصوات. ' وذكر علي مدكور أنه يجب أن تكون معالجة

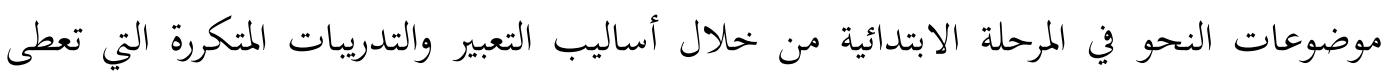

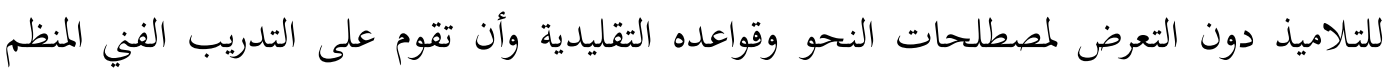

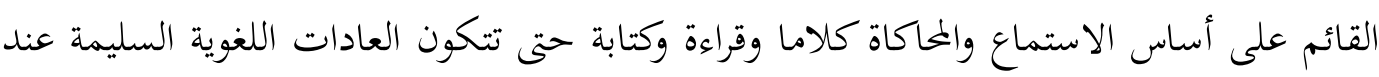
التلاميذ.

لا بد للمعلم أن يهتم بهذه الملامح قبل شروعه في تدريس القواعد، فاستعداد المعلم قبل

$$
\text { التدريس يجعل تدريسه نافعا أكثر لدى الدارسين. }
$$

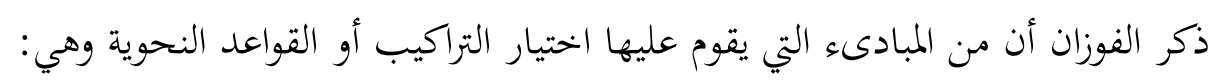
1

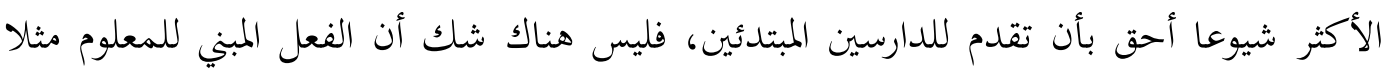

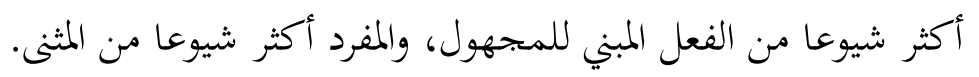

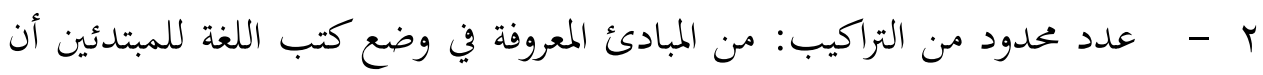
تستعمل التراكيب الجمديدة بالتدرج. r - استعمال التراكيب الجحيدة في مفردات غير جديدة: لا تستعمل التراكيب الجديدة مع مفردات جديدة إلا في الدرس الأول. ع - - التكرار: من الضروري أن تتكرر التراكيب اللغوية عددا كافيا من المرات.

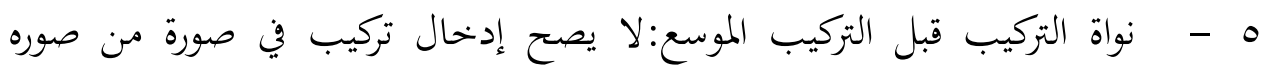
الموسعة قبل إدخاله في أبسط صورة. هذه المبادئ لا بد لمعلم العربية لغير الناطقين بها أن يهتم بها اهتماما جيدا ليسير التعليم

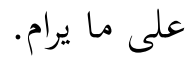

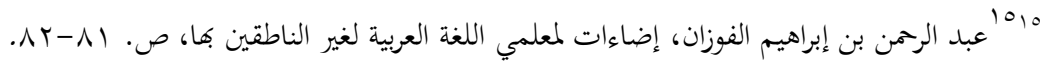

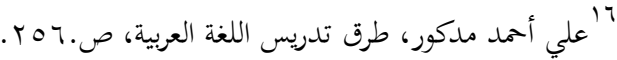

لا'انظر: داود عبده، التراكيب اللغوية في كتب تعليم العربية لغير الناطقين بها (السودان: المحلة العربية للدراسات

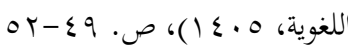

روني محمود الدين ,الطريقة المثلى في تعليم القواعد النحوية للمبتدئين والمتقدمين لغير الناطقين بها 


\section{البصيرة: مبلة الصراهات الإهلامية AL-BASHIRAH: JOURNAL OF ISLAMIC STUIDÉS \\ Vol. 1 No. 1(2020): 85-96}

Website: https://journal.stiba.ac.id

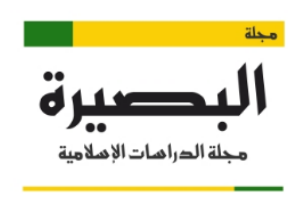

AL-BASHIRAH

قال الفوزان بأن التدريبات تعد ضرورية، فالمتعلم يراد له أن يكتسب مهارة، والمهارة تحتاج إلى تدريب ومران، وما لم تكثف التدريبات لا تتحقق السيطرة على اللغة. والتدريبات اللغوية بصورة عامة تنقسم إلى ثلاثة أقسام رئيسية هي: التدريبات الآلية والتدريبات المعنى (الدلالية) والتدريبات

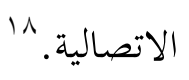

رأى الباحث أن التدريبات المناسبة للدارسين المبتدئين وهي التدريبات الآلية (الأنماط)، لأن

هذه التدريبات يتدرب بها الدارسون العادة والسلوك في استعمال اللغة بالكلام مع مراعاة التركيب النحوي التطبيقي، فتعلم الدارسون القواعد النحوية الوظيفية من خلال السياق والتكرار والمحاكاة. ذكر الفوزان أن التدريبات الآلية هي التدريبات التي يتم فيها التحكم التام في استجابة الدارس، بحيث تكون هناك استجابة واحدة هي الاستجابة الصحيحة التي على الدارس أن يأتي بها، ولأن التحكم كامل في استجابة الدارس، فهو في غير حاجة لفهم المعنى. 19 وفصل الفوزان نماذج التدريبات الآلية ومنها تدريبات الاستبدال. وذكر الفوزان أن تدريبات الاستبدال تعتبر نموذجا لهذا النشاط الآلي، حيث يقوم الدارس في هذا النوع من التدريبات بإجراء بعض التغييرات في البنية بناء على المثيرات التيى يتلقاها من المدرس. ويوضح المثال التالي، هذه الآلية

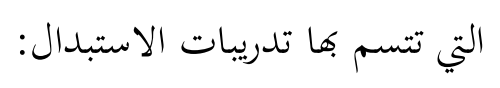

\begin{tabular}{|c|c|}
\hline (شاي) & هل عندكم ماء؟ \\
\hline (حليب) & عندكم ...؟ \\
\hline (قهوة) & \\
\hline (عصير) & \\
\hline
\end{tabular}

وتعتبر تدريبات الإعادة والترديد نموذجا لمذا النشاط الآلي كما يتضح من المثال التالي:

$$
\begin{aligned}
& \text { استمع جيدا ثم أعد الجمل التالية: } \\
& \text { أنا أكتب التقرير الأسبوعي }
\end{aligned}
$$

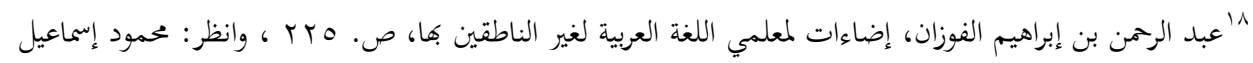

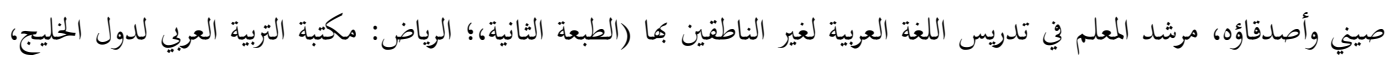

$$
\begin{aligned}
& \varepsilon r \cdot \text {. ( ) ( } 1 \varepsilon \cdot T \\
& 9 \text { أعبد الرحمن بن إبراهيم الفوزان، إضاءات لمعلمي اللغة العربية لغير الناطقين بها، ص. Oبr }
\end{aligned}
$$$$
\text { روني محمود الدين ,الطريقة المثلى في تعليم القواعد النحوية للمبتدئين والمثقدمين لغير الناطقين هما }
$$ 


$$
\text { هو هن نكتب التب التقرير الأسبوعي }
$$

وتعتبر تدريس الحوار نوعا من تدريبات الإعادة الآلية، فالدارس يستمع إلى جمل الحوار ثم

$$
\text { يأخذ في إعادة جمل الحوار خلف المدرس. }
$$

إن الهدف النهائي المتوقع من التدريبات الآلية هي سيطرة الدارس على النمط بشكل

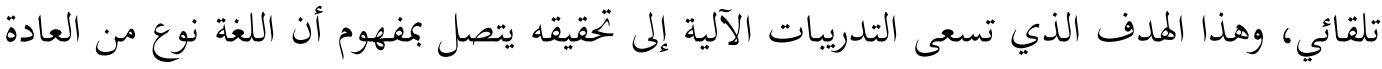

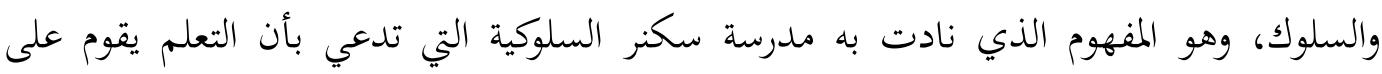

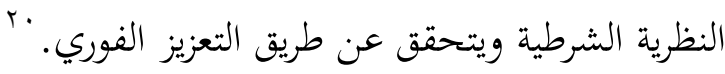
ذكر محمود إسماعيل صيني وأصدقاؤه أن هناك نوعان من التدرييات الآلية هما تدرييات

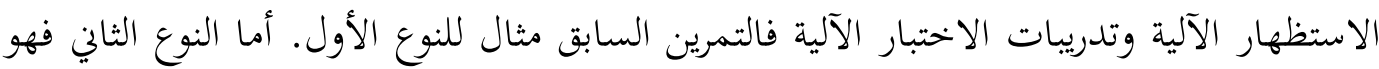

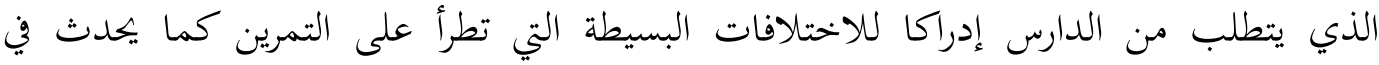

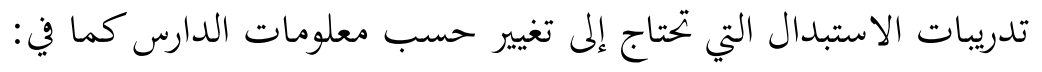

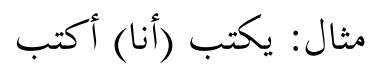

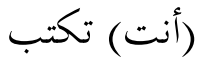

$$
\text { يقرأ (أنا) }
$$

قد يكون تدريب التحويل تدريبا آليا كما في تحويل الفعل من صيغة المبني للمعلوم إلى

$$
\begin{aligned}
& \text { صيغة المبني للمجهول، مثل: } \\
& \text { أَكل الولدُ التفاحةَ لمَّة } \\
& \text { أُكلت التفاحُُ التُ } \\
& \text { فَتح الطالبُ البابَ } \\
& \text { فُنح البابُ }
\end{aligned}
$$

وكذلك قد تكون بعض تدريبات الأسئة والأجوبة، مثل:

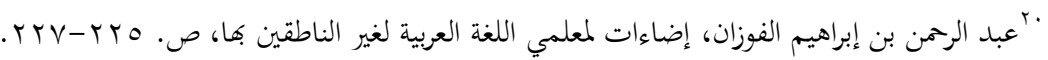




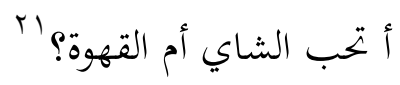

بناء على ما سبق بيانه عن التدريبات الآلية من المتخصصين في تعليم اللغة، أن

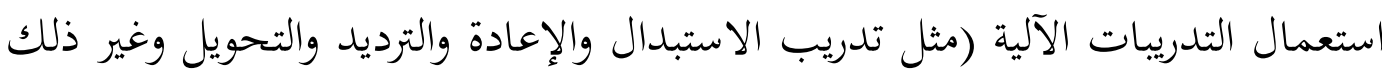
من التدريبات الآلية) في تعليم القواعد النحوية للمبتدئين لغير الناطقين بها أمر مهم لا لإنيل بد منه لتكوين العادة في الكلام لدى الدارسين. القسم الثاني: الطريقة الاستقرائية (الاستنباطية) في تعليم الاقواعد النحوية للمتقدمين لغير الناطقين بها كثيرا ما وجد في ساحة تعليم القوعد النحوية أن تعليم القواعد النحوية بحرد حفظ القواعد

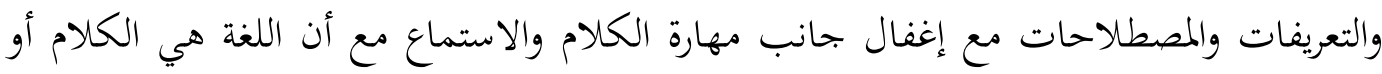
استعمال اللغة وتكوين السلوك والعادة، فذكر عبد الرممن الفوزان مراحل تعليم القواعد النحوية

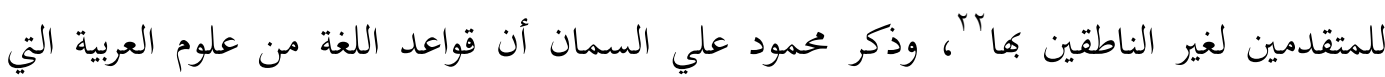

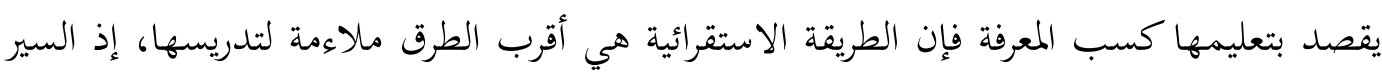

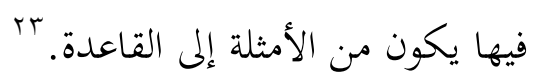
من أمثلة تدريس القواعد على الطريقة الاستقرائية كما ذكر في كتاب النحو من سلسلة العداه

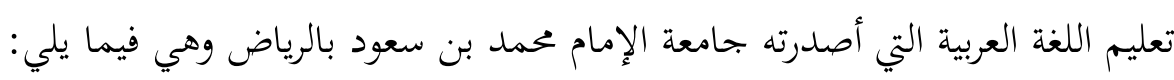

نص: عام جديد

'ابحمود إسماعيل صيني وأصدقاؤه، مرشد المعلم في تدريس اللغة العربية لغير الناطقين بها (الطبعة الثانية، الرياض:

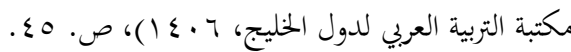

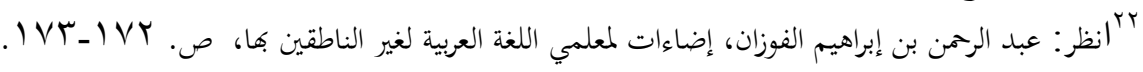

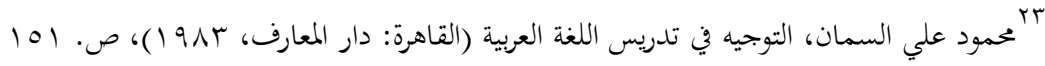
روني محمود الدين ,الطريقة المثلى في تعليم القواعد النحوية للمبتدئين والمتقدمين لغير الناطقين بها 


\section{البصيرة: مبلة الصراهات الإهلامية AL-BASHIRAH: JOURNAL OF ISLAMIC STUIDES \\ Vol. 1 No. 1(2020): 85-96}

Website: https://journal.stiba.ac.id

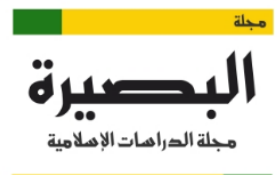

AL-BASHIRAH

خرج سعيد في الصباح من بيته، وذهب إلى معهده، سعيد طالب ياباني، وهو يتعلم اللغ العربية في معهد اللغة العربية في معهد تعليم الغة العربية في توكيو، وهو معهد كبير حوله حديقة

$$
\begin{aligned}
& \text { واسعة، فيها أشجار كثيرة وأزهار جميلة...... } \\
& \text { أسئلة الاستيعاب: } \\
& 1 \text { - - - إلى أين ذهب سعيد في الصباح؟ } \\
& \text { r - ماذا في حديقة المعهد؟ }
\end{aligned}
$$

ثم بعد هذا، يشرح المعلم القواعد التي سيدرسها الدارسون مع الربط والموازنة بين الأمثلة

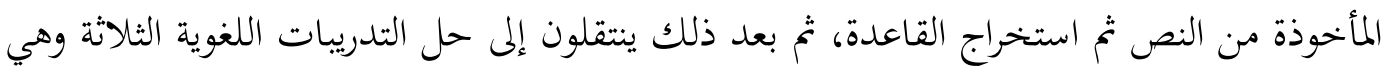

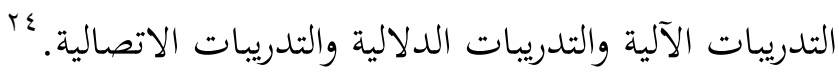

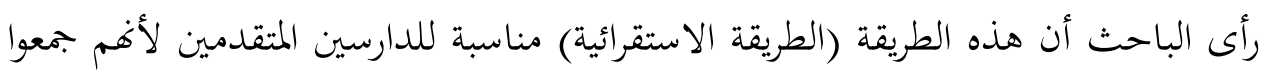

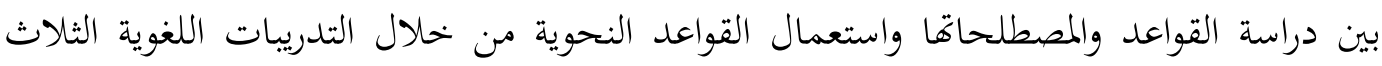
سواء كان بالكلام أو الكتابة. على المعلم مراعاة مراحل طريقة تدريس القواعد النحوية الاستقرائية، كما ذكرها الفوزان في تعليم القواعد النحوية للمتقدمين، فهذه هي المراحل التالية:

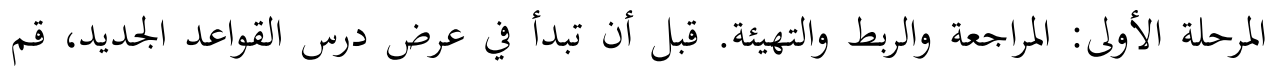

$$
\text { بمراجعة دروس القواعد السابقة. }
$$

المرحلة الثانية: المناقشة. اختبر بعض الدارسين لقراءة الأمثلة ثم قم بمناقشة الأمثلة لتتأكد أفم فهموا معانيها، وشجع الدارسين على استنباط قواعد الدرس عن طريق الحوار والأسئلة.

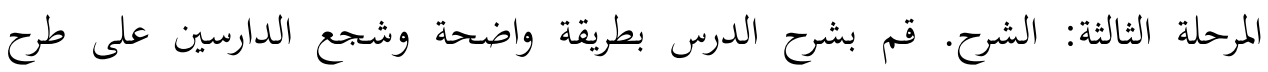
أسئلتهم. المرحلة الرابعة: القاعدة. اختر بعض الدارسين لقراءة القواعد التي سجلتها على السبورة ثم ناقشهم فيها عن طريق الأسئلة.

\$צا انظر : أمد مرغني عيسوي، سلسلة تعليم اللغة العربية - كتاب النحو للمتسوى الثاني- (الرياض: جامعة الإمام

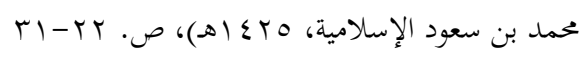

روني محمود الدين ,الطريقة المثلى في تعليم القواعد النحوية للمبتدئين والمتقدمين لغير الناطقين بما 


\section{البصيرة: مبلة الصراهات الإهلامية AL-BASHHIRAH: JOURNAL OF ISLAMIC STUIDES \\ Vol. 1 No. 1(2020): 85-96}

Website: https://journal.stiba.ac.id

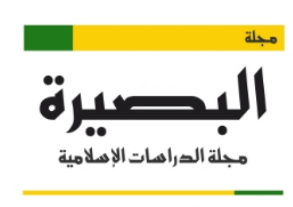

AL-BASHIRAH

المرحلة الخامسة: التدريبات. انتقل إلى مرحلة التدريبات متبعا الأساليب المختلفة

$$
\text { ro. لإجرائها. }
$$

ذكر محمود كامل الناقة أن تدريس قواعد اللغة للمتعلم يمكن يحقق هدفين هما: الهدف الأول: أن تدريس القواعد للمبتدئين ينبغي أن يوجد إحساسا لغويا صادقا وطليقا

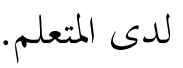

الهدف الثاني: أما في المستويات المتقدمة وعندما تمت السيطرة على اللغة إجرائيا ينبغي أن

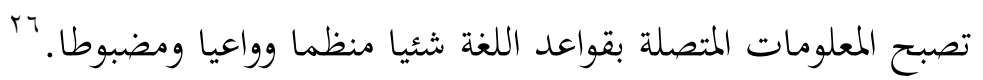
هناك ثلاث التدريبات اللغوية في تعليم القواعد النحوية للمتقدمين لغير الناطقين بها، وهي

$$
\text { التدريبات الآلية والتدريبات الدلالية والتدريبات الاتصالية. }
$$

أما نماذج التدريبات الآلية فقد ذكرها الباحث في المبحث عن طريقة تدريس القواعد النحوية للمبتدئين. فالتدريبات الآلية مهم أيضا للمتقدمين لأجل تكوين العادة لدى الدارسين، ولكن لا تعطى هذه التدريبات بكثرة لأفم قد مروا بهذه التدريبات في المرحلة الابتدائية. وذكر الفوزان أن تدريبات المعنى (الدلالية) لا يزال هناك نوع من التحكم في استجابة الدارس إلى أن الدارس في هذه التدريبات يمكنه التعبير عن المعنى بأكثر من طريقة وهي في هذا تختلف عن التدريبات الآلية التي تخلو تماما من عنصر الاختيار. وكذلك تدريبات المعنى تختلف عن التدريبات الآلية من الناحية الإجرائية، فالأولى تؤدى فرديا فقط أما التدريبا الآلية فيمكن أداؤها فرديا وجماعيا وفي بحموعات صغيرة. بناء على هذا تبين أن تدريبات الدلالية (المعنى) مهمة جدا لدى الدارسين بعدما تعودوا

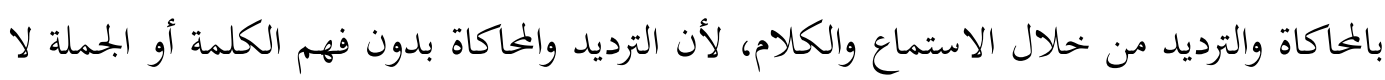
تنفع كثيرا لأن اللغة هي الكلام مع الفهم.

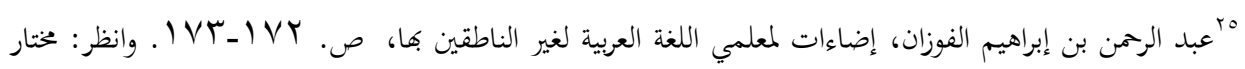

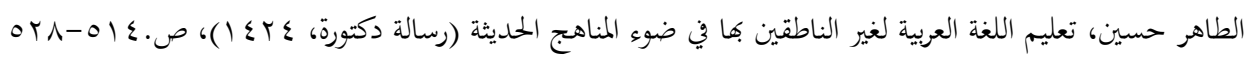

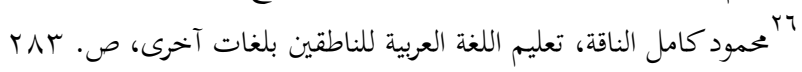

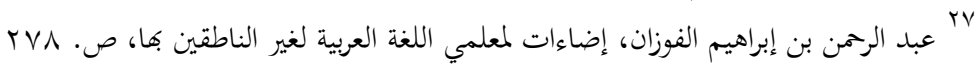$$
\text { روني محمود الدين ,الطريقة المثلى في تعليم القواعد النحوية للمبتدئين والمتقدمين لغير الناطقين بها }
$$ 
وخير مثال لتدريبات المعنى كما ذكره الفوزان، تدريبات السؤال والجواب التي تستخدم عادة

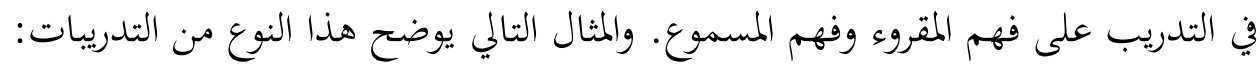
نص: (( حضر السيد فريد من السودان إلى القاهرة، درس اللغة العربية في جامعة القاهرة،

$$
\begin{aligned}
& \text { وبعد الدراسة رجع إلى السودان، وهو الآن موظف كبير في الخرطوم)) } \\
& \text { أسئلة: }
\end{aligned}
$$

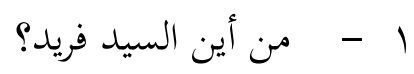

$$
\begin{aligned}
& \text { r } \\
& \text { r - - هل حصل على شهادة جامعية؟ } \\
& \text { ع - - هل هو طالب الآن؟ }
\end{aligned}
$$

من التدريبات الآلية المناسبة في تعليم القواعد النحوية للمتقدمين هي التدرييات الاتصالية.

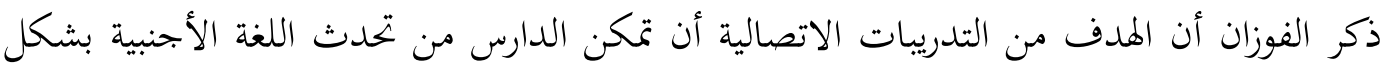
عادي وأن بتعله قادرا على فهم ما يسمع دون خطأ، وبهذا يتحقق الاتصال بينه وبيه أهل اللغة الغنة

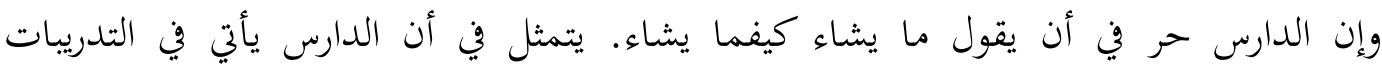

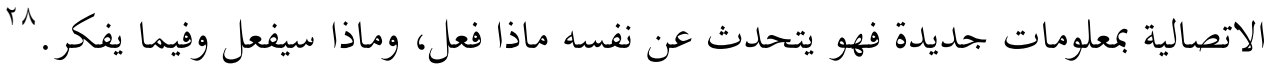

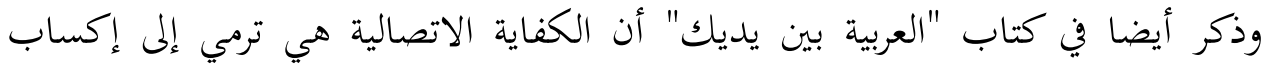

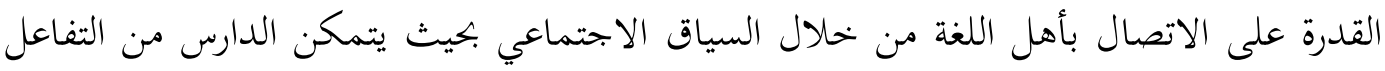

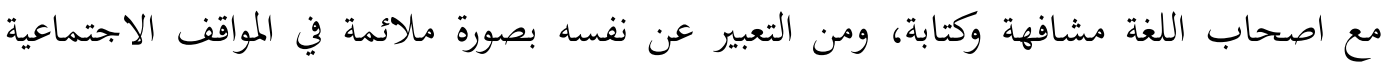

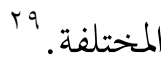

في التدريبات الاتصالية فالدارس يأتي بمعلومات جديدة لا يعرفها أحد من المخيطين به كما

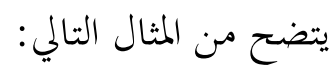

$$
\begin{aligned}
& 1 \\
& \text { r - - مل كان والدك موجودا؟ } \\
& \text { r - هل شاهدت التلفاز؟ }
\end{aligned}
$$

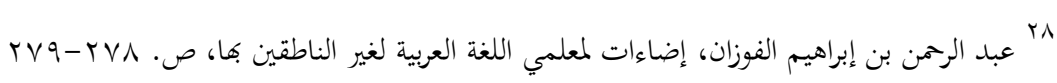

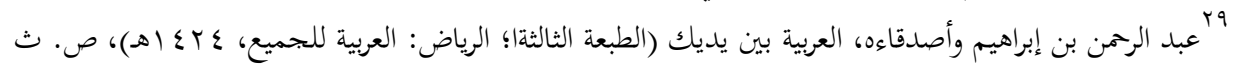




\section{البصيرة: مبلة الصراهات الإهلامية AL-BASHHIRAH: JOURNAL OF ISLAMIC STUIDES \\ Vol. 1 No. 1(2020): 85-96}

Website: https://journal.stiba.ac.id

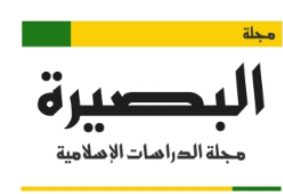

AL-BASHIRAH

$$
\text { ع - - م كم ساعة استذكرت دروسك؟ }
$$

إن تدريبات الاتصال تخرج عن إطار المفاهيم التي طرحها سنكر وأتباعه من السلوكيين حيث لا تنطلق من القول بأن تعلم اللغة عبارة تأسيس لعادة، ويمكن القول بأن فكرة جون كارول التي تنادي بأن التعلم عبارة عن حل لمشكلة كان لها أثر كبير في ظهور التدريبات الاتصالية. وبناء على ما تقدم يمكن القول بأن المنهج الصحيح لتعليم اللغة العربية هو المنهج الذي يستخدم الأنواع الثلاثة من التدريبات السابقة في تكامل وتوازن. r. فالطريقة الاتصالية مناسبة للدارسين المتقدمين بعد أن كانوا تعودوا باستعمال اللغة من خلال المحاكاة والتردير وقد درسوا أيضا القواعد النحوية من السياق. ولذا فلا بد من استعمال هذه الطريقة في تعليم القواعد النحوية، إذ أن تعليم القواعد بدون استعمال هذه القواعد في الكلام لا ينفع كثيرا، لأن الهدف من تعليم القواعد هو صون اللسان من الخطأ في الكلام، وليس بحرد حفظ القواعد ومصطلحاقها. فالتوازن في استعمال التدريبات الثلاث في تعليم القواعد النحوية (تدريبات الأنماط والدلالة والاتصال) أمر لا بد منه لتكوين الدارسين متمكين في استعمال اللغة بالطلاقة مع مراعاة صحة القواعد.

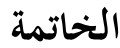

$$
\text { قبل ختم هذا البحث، فذكر الباحث بعض التلخيصات حول الموضوع فيما يلي: }
$$

الأول: الطريقة المثلى في تعليم القواعد النحوية لغير اللدارسين المبتدئين لغير الناطقين به،ا هي طريقة السمعية الشفهية (الطريقة العرضية) مع الإكثار في تدريبات الأنماط (الآلية) لتكوين العادة والسلوك كلاما كان أم استماعا لدى الدارسين مع عرض القواعد النحوية التطبيقة لا النظرية، بحيث أن الدارسين تعلموا القواعد النحوية في هذه الطريقة من خلال السياق. الثاني: الطريقة المثلى في تعليم القواعد النحوية للدارسين المتقدمين لغير الناطقين بها، هي الطريقة الاستقرائية (الطريقة القاصدة)، وهي الطريقة التي جعلت النص الحواري أو المقروئي محورا لأنشطة اللغة كلاما أو قراءة تتعلق بالقواعد النحوية، مع استصحاب التدريبات اللغوية الثلاث 


\section{البصيرة: مبلة الصراهات الإهلامية AL-BASHIRAH: JOURNAL OF ISLAMIC STUIDÉS \\ Vol. 1 No. 1(2020): 85-96}

Website: https://journal.stiba.ac.id

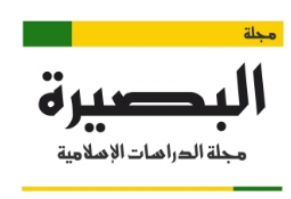

AL-BASHIRAH

المبنية على النص المحوري، وهيى التدريبات الآلية والدلالية والاتصالية لتكوين العادة والسلوك مع عرض القواعد النحوية النظرية والتطبيقية لدى الدارسين.

\section{فهرس المصادر والمراجع}

- ابن تيمية الحراني. (9 إ(هـ/9991م). اقتضاء الصراط المستقيم. دون الطبعة؛ بيروت: دار عالم

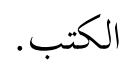

- أحمد مرغني عيسوي. (كro اهـ). سلسلة تعليم اللغة العربية - كتاب النحو للمتسوى الثاني-.

$$
\text { الرياض: جامعة الإمام محمد بن سعود الإسلامية. }
$$

ديجة ميداني، (1) ·rr). طرائق تدريس النحو. رسالة الماجستير، جامعة أحمد دراية، الجزائر. داود عبده. (0.ـعاهـ). التراكيب اللغوية في كتب تعليم العربية لغير الناطقين بما. السودان: المجلة

$$
\text { العربية للدراسات اللغوية. }
$$

السيد أحمد الهاشمي. (19V| (ام). القواعد الأساسية للغة العربية. بيروت: دار الكتب العلمية.

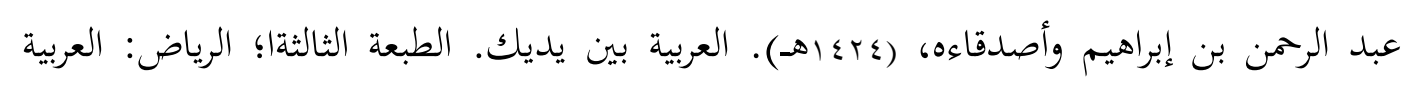
للجميع.

عبد الرحمن بن إبراهيم الفوزان. (rr\& (هـ) إضاءات لمعلمي اللغة العربية لغير الناطقين بها. ط.|: الرياض: مكتبة الملك فهد الوطنية.

عبد العليم إبراهيم. (1ی اهـ). الموجه الفني لملدرسي اللغة العربية. ط. • إ: القاهرة: دار المعارف. علي أحمد مدكو. (rv (هـ). طرق تلدريس اللغة العربية. ط. ا: عمان: دار المسيرة. محمود إسماعيل صيني وأصدقاؤه. (7 .ع ا هـ). مرشد المعلم في تلدريس اللغة العربية لغير الناطقين كما. ط.ب،: الرياض: مكتبة التربية العربي لدول الخليج.. محمود تيمو. (دون سنة). مشكالات اللغة العربية. دون الطبعة؛ بيروت: منشورات المكتبة العصرية. محمود علي السمان. (ra/9 ام). التوجيه في تلدريس اللغة العربية. القاهرة: دار المعارف.

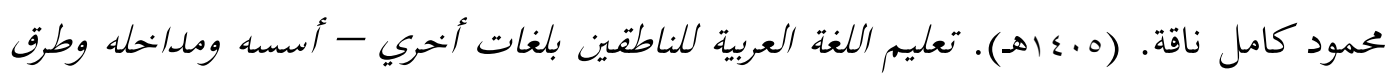
تلدريسه -. دون الطبعة؛ المملكة العربية السعودية: جامعة أم القرى وزارة التعاليم العالي. 
البصيرة: مبلة الصراهات الإهلامية AL-BASHIRAH: JOURNAL OF ISLAMIC STUIDES

Vol. 1 No. 1(2020): 85-96

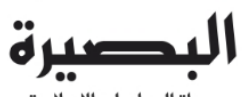

مجلة الصراعات الإصلامية

AL-BASHIRAH

Website: https://journal.stiba.ac.id

JOURNAL OF ISLAMIC STUDIES

مختار الطاهر حسين. (ع اءا هـ). تعليم اللغة العربية لغير الناطقين كما في ضوء المناهج الحلديثة. رسالة دكتورة.

روني محمود الدين ,الطريقة المثلى في تعليم القواعد النحوية للمبتدئين والمتقدمين لغير الناطقين بها 